\title{
PARENTAL EDUCATIONAL STYLES AS PREDICTORS OF PERFECTIONISM AND QUALITY OF SIBLING RELATIONSHIPS AMONG STUDENTS
}

\author{
Danijela Randjelovic, Jelisaveta Todorovic, \& Miljana Spasic Snele \\ Department of Psychology, Faculty of Philosophy University of Nis (Serbia)
}

\begin{abstract}
The main objective of this study was to examine the relationship between parental educational styles, perfectionism in children, and the quality of adult sibling relationships. Additionally, the goal is to determine whether parental educational styles represent a significant predictor of perfectionism and quality of relationship between adults. The research was conducted on a sample of 200 respondents, students of the Faculty of Philosophy, the Faculty of Economics and the Faculty of Sciences and Mathematics in Nišs. EMBU questionnaires were used to examine the parental educational styles, the Multidimensional Perfectionism Scale (MPS), and the KOBS Questionnaire on the quality of relationships with siblings in adulthood. The starting hypotheses have been partially confirmed and new questions have been raised about these constructs and their relationship.

Statistically significant predictors of different aspects of perfectionism that were measured were a) significant predictors for the aspect of Parental Expectations were the following parental educational styles Overprotective mother $(\beta=0.375, \mathrm{p}=0.003)$ and Father's Favoritism $(\beta=-0.186, \mathrm{p}=0.035)$, b) a significant predictor for the aspect of Organization was the following educational style Mother's Emotional Warmth $(\beta=0.335, p=0.031)$; $)$ significant predictors for Parental Criticism were the following educational styles Father's Rejection $(\beta=0.254, p=0.009)$ and Mother's Emotional Warmth $(\beta=-0.437$, $\mathrm{p}=0.000), \mathrm{d})$ the significant predictor of Personal Standards was Overprotective mother $(\beta=0.307$; $\mathrm{p}=0.042$ ), e) significant predictors for Concern over Mistakes, were the following educational styles Parental Inconsistency $(\beta=0.160 ; p=0.048)$ and Mother's Emotional Warmth $(\beta=-0.308, p=0.027)$, f) significant predictors of Doubts about Actions were the following educational styles, Parental Inconsistency $(\beta=0.235, \mathrm{p}=0.007)$, Overprotective mother $(\beta=0.304, \mathrm{p}=0.035)$ and Mother's Favoritism $(\beta=0.222, p=0.028)$. When it comes to the quality of relationship between brothers and sisters, parental educational styles are also significant predictors of various aspects of those relationships. We are pointing out the most important results. Statistically significant predictors of the subscale Competition between siblings were the educational styles Father's Rejection ( $\beta=0.469, \mathrm{p}=0.000)$, Mother's Favoritism ( $\beta=0.475$, $\mathrm{p}=0.000$ ), Father's Favoritism ( $\beta=-0.196, \mathrm{p}=0.029)$, and Mother's Emotional Warmth $(\beta=-0.313, \mathrm{p}=0.019)$. Statistically significant predictors for the subscale Closeness or Warmth between siblings were the following educational styles Mother's Rejection $(\beta=-0.456, p=0.006)$ and Father's Emotional Warmth $(\beta=0.391, \mathrm{p}=0.002)$. Statistically significant predictors for subscale the Conflict between siblings were the following educational styles Father's Rejection $(\beta=0.355, p=0.003)$ and Mother's Favoritism $(\beta=0.337$, $\mathrm{p}=0.000$ ). These results show that both rejection and favoritism by the parents contribute to the development of less desired relationships between siblings. Overprotective parents, inconsistency and favoritism of a child contribute to less desired aspects of perfectionism. Additional analysis of connection between perfectionism and relationship between siblings revealed that the less desired aspects of perfectionism are connected with bad relationships between siblings. The only exception is the aspect of Organization as it is connected with emotional and instrumental support, familiarity, closeness and admiration between siblings.
\end{abstract}

Keywords: Educational styles, perfectionism, quality of sibling relationships, family.

\section{Introduction}

Hollender (1965; as cited in Cook, 2012) points out that perfectionism involves placing excessive demands on oneself and the feeling that everything but the perfect performance is unacceptable. The desire to improve one's self-image and to be accepted by others is the basic motivation of perfectionism. The main problem with this definition of perfectionism is that it does not distinguish perfectionists from people who are highly competent and successful, given that setting and striving for high standards is not in itself a 
pathological phenomenon (Blatt, D’Afflitti, \& Quinlan, 1976, as cited in Frost et al., 1990). Let us also mention that Schneider (according to Frost et al., 1990) considered that excessively high standards are the cause of the basic feeling of inadequacy in compulsive people. Among many definitions of perfectionism, we single out the one proposed by Flett and Hewitt (1992), which emphasizes that perfectionism is the pursuit of infallibility, and extreme perfectionists are people who want to be perfect in every aspect of their lives.

Flett et al. (2002) in Theory, Research, and Treatment indicate that some children become perfectionists due to their exposure to adverse life events. Children who are physically or mentally abused or who grew up in overly chaotic families realize that their parents are unreliable and, in response to difficult circumstances, these children may develop perfectionism for two reasons. The first one is to avoid future abuse and humiliation, and the second one is to control an otherwise unpredictable environment. By behaving in a perfect way, they protect themselves both by meeting the standards of the most demanding parents, and by reducing the number and severity of conflicts with important people in their lives. Hamachek (1978) also believed that if parents do not set the standards for their children and do not give appropriate feedback on children's performance, children can set unrealistically high standards for themselves.

Kenney-Benson and Pomerantz (2005, as cited in Cook, 2012) found that children whose mothers show hostility and criticism towards them while performing a demanding task develop socially prescribed perfectionism. Clark and Coker (2009) found a similar association between maternal criticism and dysfunctional child perfectionism. These studies are in line with the idea that perfectionism can be developed as a protective mechanism in cases of parental abuse. Cook and Kearney (2008) suggest that the symptoms of depression, obsessive-compulsive disorder, and anxiety in mothers predict the development of self-centered perfectionism in male children. Children will develop perfectionism if parents behave too protectively, overemphasize the importance of positive impressions in relation to others, often remind them of the danger of wrong decisions, point to a sharp condemnation of mistakes by others (Flett et al, 2002). Symptoms of anxious parents such as an obsession with cleanliness and tidiness, and constant worry are often parental symptoms associated with perfectionism in children.

Ablard and Parker (1997) examined children's perfectionism and parents' achievement goals. Parents were divided into those who were guided by learning goals and those who valued the goals of achieving success. In accordance with the model of social expectations, more children whose parents were oriented towards the goals of achieving success were classified in the group of those with high perfectionism.

Educational style has also been shown to be a significant factor associated with the development of perfectionism. In accordance with the Social Expectation Theory, it has been shown that parents who demand the best performance and complete obedience tend to have their offspring adopt the characteristics of maladaptive perfectionism (Speirs Neumeister \& Finch, 2006, according to Cook, 2012). In order to better understand the contribution of parenting styles to children's development, it is good to distinguish between parenting styles and parenting practices (Steinberg \& Silk, 2002, according to Roboteg-Šarić et al., 2011). Parental educational style refers to the emotional context within which the interaction of the child and parent takes place and is defined by different dimensions, while parenting practices are specific goal-oriented behaviors and activities aimed at socializing the child in a certain way, more or less independent of parenting styles (Roboteg-Šarić et al., 2011). We also emphasize that the educational style of both father and mother has an important role in the development of the child, as indicated by numerous authors (Cox \& Harter, 2003, Lamb et al., 2005, according to Roboteg-Šarić et al., 2011). Of course, the parental educational style, although most often constant in different periods of children's growth, still contributes differently to the formation of personality in childhood, adolescence and early adulthood.

When we talk about the role of parental educational style in encouraging maladaptive and adaptive perfectionism, the question of how perfectionism is related to the relationship with siblings in the family, especially during adolescence, seems justified. Does the pursuit of perfection perhaps lead to rivalry with siblings in an effort to gain recognition and praise from parents and significant others? Perhaps the parental educational style contributes to the competition among siblings and at the same time the insatiable need to be perfect and ahead of everyone? Undoubtedly, in the period of the formation of identity and independence in relation to the parent, the relationship with siblings plays a significant role.

Namely, the relationship with a brother/sister is for most people the longest-lasting interpersonal relationship (Ćubela Adorić and Jurkin, 2006). When talking about the psychological development and life of a child, his/her relationship with the mother is most often commented on, less frequently the relationship with the father is mentioned, and the least, only sometimes, the relationship with siblings. Still, this relationship can be very important for the experience of one's own continuity and for the subjective well-being during later periods of development (Bedford, 1989, Brody, 1998, Cicirelli, 1991, Connidis, 2001, Norris \& Tindale, 1994, according to Ćubela Adorić and Jurkin, 2006). According to Vera Ćubela 
Adorić and Marina Jurkin (2006), there are three basic dimensions that assess the quality of relationships with siblings in adulthood: Warmth, Conflict and Rivalry. Their research found a statistically significant negative correlation between Warmth and Conflict, a positive correlation between Rivalry and Conflict, as well as a negative correlation between Rivalry and Warmth (Ćubela Adorić and Jurkin, 2006). In addition, the relationship with a sister is assessed as closer and less competitive than the relationship with a brother. Compared to male respondents, female respondents perceive less competition, and more approval and rivalry in the relationship with their brother or sister. Mother's favoritism was most prevalent in the brother-sister relationship category (Ćubela Adorić and Jurkin 2006).

\section{Objectives}

The overall objective is to examine whether a certain percentage of the variability of perfectionism and the quality of sibling relationships in late adolescence can be explained based on educational styles. In addition, we set an objective to examine the relationship between perfectionism and sibling relationships in late adolescence.

\section{Methods}

\subsection{Sample}

The sample was appropriate and consisted of 200 final-year students of the Faculty of Philosophy, Faculty of Sciences and Mathematics and Faculty of Economics in Niš, equalized by gender. Of the total sample, $85.5 \%$ (171) are respondents whose family has two children, then $6 \%$ (12) are respondents who come from families with three children, and $8.5 \%$ (17) from families with more than three children. A quarter $(25 \%-50)$ of the sample consists of the respondents whose sibling is brother-brother, then $21.5 \%$ (43) of the respondents with the sibling sister-sister, and 53.5\% (107) of the respondents have the sibling brother-sister.

\subsection{Instrument}

To assess perfectionism, the Multidimensional Perfectionism Scale (MPS; Frost, Marten, Lahart, $\&$ Rosenblate, 1990) was used, which contains 35 claims. The scale provides information on the overall score of perfectionism, as well as information on the severity of six aspects of perfectionism: Concern over Mistakes (9 items), Personal Standards (9 items), Parental Expectations (5 items), Parental Criticism (4 items), Doubts about Actions (4 items), Organization (6 items). The MPS scale has good metric characteristics: the reliability coefficient of the total score on the scale as a whole (estimated by the Cronbach's internal consistency coefficient) is $\alpha=0.88$, and the reliability of the subscales ranges from $\alpha=0.73-0.89$.

To assess the quality of sibling relationships, the Questionnaire on the quality of relationships with siblings in adulthood was used (KOBS; Ćubela Adorić and Jurkin, 2006). The scale consists of 81 items, and the questionnaire is of satisfactory reliability (Ćubela Adorić and Jurkin, 2006). In the student sample, the reliability of the Warmth scale is 0.92 , Conflict 0.90 and Rivalry 0.64 . The subscales are also of satisfactory reliability: Quarrel $(\alpha=0.78)$; Antagonism $(\alpha=0.88)$; Competition $(\alpha=0.85)$; Dominance $(\alpha=0.73)$; Similarity $(\alpha=0.87)$; Intimacy $(\alpha=0.90)$; Affection $(\alpha=0.93)$; Admiration $(\alpha=0.82)$; Emotional support $(\alpha=0.88)$; Instrumental support $(\alpha=0.70)$; Acceptance $(\alpha=0.90)$; Paternal Favoritism $(\alpha=0.94)$; Maternal Favoritism $(\alpha=0.92)$.

To assess parental educational styles, the EMBU scale was used, which was constructed by the Swedish researcher (Perris et al., 1980). Arrindell and coworkers in the Netherlands (1983) performed the most comprehensive scale check and at a higher level of factorization singled out 4 pure factors: rejection, overprotection, emotional warmth, and favoritism. The EMBU questionnaire was tested on the Serbian adolescent population (third-grade high school students in Belgrade, Šaula, 1989). Regarding the Inconsistency Subscale added by Šaula, that subscale proved to be partially independent of those already existing in the instrument. The research confirmed a high internal consistency and "transculturality" of this test. The reliability of the subscales ranges from $\alpha=0.72$ to 0.92 , while the scales Mother's Favoritism $(\alpha=0.59)$ and Father's Favoritism $(\alpha=0.69)$ are below the reliability limit.

\section{Results}

Given that a lot of data was obtained in this study, the most important findings will be presented in a table, primarily the correlations between the parental educational styles, perfectionism and the dimensions of the quality of the relationships between siblings. The most significant results of regression analysis are singled out and presented in text. 
Table 1. The connection between parenting styles and perfectionism-MPS total, that is, the dimensions of the quality of the relationship between siblings (Pearson's correlation coefficient).

\begin{tabular}{|l|c|c|c|c|}
\hline & MPS total & Conflict & Rivalry & Warmth \\
\hline Parental Inconsistency & $0.465^{* *}$ & $0.228^{* *}$ & $0.228^{* *}$ & $-0.189^{* *}$ \\
\hline Mother's Rejection & $0.507^{* *}$ & $0.319^{* *}$ & 0.121 & $-0.311^{* *}$ \\
\hline Father's Rejection & $0.500^{* *}$ & $0.381^{* *}$ & $0.139^{*}$ & $-0.297^{* *}$ \\
\hline Mother's Overprotection & $0.525^{* *}$ & 0.119 & -0.035 & -0.036 \\
\hline Father's Overprotection & $0.387^{* *}$ & 0.047 & 0.004 & 0.052 \\
\hline Mother's Favoritism & 0.125 & $0.357^{* *}$ & $-0.118^{* *}$ & -0.100 \\
\hline Father's Favoritism & 0.077 & $0.302^{* *}$ & $-0.239^{* *}$ & -0.098 \\
\hline Mother's Emotional Warmth & $-0.315^{* *}$ & $-0.180^{*}$ & $-0.163^{*}$ & $0.289^{* *}$ \\
\hline Father's Emotional Warmth & $-0.303^{* *}$ & $-0.173^{*}$ & $-0.140^{*}$ & $0.340^{* *}$ \\
\hline
\end{tabular}

Table 2. Relationship between the dimensions of perfectionism and the dimensions of the quality of relationships between siblings in adulthood.

\begin{tabular}{|l|c|c|c|c|c|c|}
\hline & $\begin{array}{c}\text { Concern } \\
\text { over } \\
\text { Mistakes }\end{array}$ & $\begin{array}{c}\text { Personal } \\
\text { Standards }\end{array}$ & $\begin{array}{c}\text { Parental } \\
\text { Expectations }\end{array}$ & $\begin{array}{c}\text { Parental } \\
\text { Criticism }\end{array}$ & $\begin{array}{c}\text { Doubts } \\
\text { about } \\
\text { Actions }\end{array}$ & Organization \\
\hline Conflict & $0.278^{* *}$ & $0.192^{* *}$ & $0.194^{* *}$ & $0.205^{* *}$ & $0.265^{* *}$ & -0.083 \\
\hline Rivalry & 0.034 & -0.030 & 0.017 & 0.059 & 0.040 & -0.096 \\
\hline
\end{tabular}

**Significant at the level of 0.01

*Significant at the level of 0.05

When it comes to warmth in the relationships between siblings, we obtained a significant correlation with the results of the perfectionism scale as a whole $\left(r=-0.156^{*}, \mathrm{p}>0.05\right)$.

Table 3. The correlation between the Perfectionism subscale-MSP total and the Warmth dimension (KOBS) (Pearson's correlation coefficient).

\begin{tabular}{|c|c|}
\hline & MPS total \\
\hline Warmth & $-0.156^{*}$ \\
\hline \multicolumn{2}{|c|}{ **Significant at the level of 0.01} \\
*Significant at the level of 0.05
\end{tabular}

Statistically significant predictors of different aspects of perfectionism. Significant predictors of the aspect of Parental Expectations were parental educational styles Overprotective mother ( $\beta=0.375$, $\mathrm{p}=0.003)$ and Father's Favoritism $(\beta=-0.186, \mathrm{p}=0.035)$; the significant predictor of Organization was the educational style Mother's Emotional Warmth $(\beta=0.335, \mathrm{p}=0.031)$; significant predictors for Parental Criticism were educational styles Father's Rejection $(\beta=0.254, \mathrm{p}=0.009)$ and Mother's Emotional Warmth $(\beta=-0.437, p=0.000)$; the significant predictor of Personal Standards was Overprotective mother $(\beta=0.307, p=0.042)$; significant predictors for Concern over Mistakes were the educational styles Parental Inconsistency $(p=0.048, \beta=0.160)$ and Mother's Emotional Warmth $(\beta=-0.308, p=0.027)$; significant predictors of Doubts about Actions were the following educational styles, Parental Inconsistency $(\beta=0.235$, $\mathrm{p}=0.007)$, Overprotective mother $(\beta=0.304, \mathrm{p}=0.035)$ and Favoritism by the Mother $(\beta=0.222, \mathrm{p}=0.028)$. When it comes to the quality of relationship between brothers and sisters, parental educational styles are also significant predictors of various aspects of those relationships. We are pointing out the most important results. Statistically significant predictors of the subscale Competition between siblings were the educational styles Father's Rejectio ( $\beta=0.469, \mathrm{p}=0.000$ ), Mother's Favoritism $(\beta=0.475, \mathrm{p}=0.000)$, Father's Favoritism $(\beta=-0.196, p=0.029)$, and Mother's Emotional Warmth $(\beta=-0.313, p=0.019)$. Statistically significant predictors for the subscale Closeness or Warmth between Siblings were the following educational styles Mother's Rejection $(\beta=-0.456, p=0.006$, ) and Father's Emotional Warmth $(\beta=0.391$, $\mathrm{p}=0.002$ ). Statistically significant predictors for the subscale Conflict between siblings were the following educational styles Father's Rejection ( $\beta=0.355, \mathrm{p}=0.003)$ and Mother's Favoritism $(\beta=0.337, \mathrm{p}=0.000)$. 


\section{Discussion}

The main goal of this study was to examine whether perfectionism and the quality of sibling relationships in late adolescence can be explained based on parenting styles of both mother and father.

According to the results, we can notice that Overprotective Mother has a negative role in the development of some aspects of perfectionism, such as Parental Expectations and Personal Standards, but also Doubts about Actions. Nevertheless, Parental Inconsistency contributes to Concern over Mistakes and Doubts about Actions, in which Mother's Favoritism also has an important role. We would like to stress that Father's Favoritism decreases Parental Expectations, whereas Father's Rejection is correlated with the perception of higher Parental Criticism. On the other hand, Mother's Emotional Warmth represents an adequate context of the development of Organization, whereas growing up of adolescents in such emotional atmosphere will be less burdened with Concern over Mistakes, and Parental Criticism.

Obtained results are in accordance with some previous findings. Namely, Flett et al. (2002) point out that children will develop perfectionism if parents are overprotective, overemphasize the importance of positive impressions in relation to others, often remind children of the dangers of wrong decisions, as well as point out the sharp condemnation of mistakes by others. Hamachek (1978) also believed that if parents do not set standards for their children and do not give appropriate feedback on children's performance, children can set unrealistically high standards for themselves. Based on that, as well as on our results, it could be said that positive experiences in relation with parents followed by parental emotional warmth represent an adequate background for the development of adolescents who will not be burdened with achieving unrealistic goals.

When it comes to sibling relations, it was shown that rejection from both mother and father, but also Mother's Favoritism, are significant factors in the perception of sibling relations, disrupting them by encouraging competition and conflicts between siblings. A particularly interesting result is that Father's Favoritism is negatively correlated with competition in the sibling relationship. Father's Emotional Warmth is a significant factor of the experience of warmth between siblings, whereas Mother's Rejection decreases emotional warmth between siblings. In line with that, it could be said that qualitative relationship and experience of acceptance from both father and mother represent significant predictors of good relations between siblings, thus confirming numerous previous findings (Cox \& Harter, 2003; Lamb et al., 2005; as cited in Roboteg-Šarić et al., 2011).

\section{Conclusion}

Summarizing the obtained results, first we would like to point out that both the father and the mother and their parental educational styles have an important role when it comes to adolescent development. Parental emotional warmth and acceptance are predispositions for developing adequate perfectionism and good relations with siblings. On the other hand, overprotective mother and parental inconsistency contribute to destructive perfectionism in adolescents, whereas rejection from both the mother and the father, and mother's favoritism (but not the father's) encourage competition and conflicts between siblings.

\section{References}

Clark, S., \& Coker, S. (2009). Perfectionism, self-criticism and maternal criticism: A study of mothers and their children. Personality and Individual Differences, 47(4), 321-325.

Cook, L.C. (2012). The influence of Parent Factors on Child Perfectionism: A Cross- Sectional Study.

Ćubela Adorić, V. I Jurkin, A. (2006). Upitnik kvaliteta odnosa sa braćom i sestrama u odraslom dobu (KOBS). U: Ćubela Adorić, V., Penezić, Z., Proroković, A. I Tucak, I. (Ur.), Zbirka psihologijskih skala i upitnika. Svezak 3, Zadar: Filozofski fakultet. 75-86

Ćubela Adorić, V., Jurkin, M. (2006). Qualities of sibling relationships from adolescence to late adulthood.

Enns, M. W.., Cox, B.J., Sareen, J., \& Freeman, P. (2001). Adaptive and maladaptive perfectionism in medical students: a longitudinal investigation. Medical education, 35 (11), 1034-1042.

Flett, G. L., Hewitt, P. L. (2002). Theory, Research, and Treatment, Washington, DC, American Psychological Association,

Frost, R.O., Marten, P., Lahart, C., \& Rosenblate, R. (1990). The dimensions of perfectionism. Cognitive therapy and research 14 (5), 449-468.

Hamachek, D. E. (1978) Psychodynamics of Normal and Neurotic Perfectionism. Psychology, 15, 27-33.

Roboteg Šarić, Z., Merkaš, M. i Majić, M. (2011). Nada i optimizam adolescenata u odnosu na roditeljski odgojni stil. Napredak, 152 (3-4), 373-388 